characterisation, injury types and identify the aggressor-victim relationship.

Materials and Methods A series of cases, defined case: Any woman attended by Marcala IML, physical, mental or sexual domestic violence victim, on June 11th 2007 to November 30th, 2009. All medical records in IML were reviewed, developed a sheet to collect variables data: age, origin, marital status, educational level, profession or occupation, race, type of violence, injury, instrument of injury, disability granted, sequels, relationship with the perpetrator; calculated central tendency and frequency measures.

Results Reviewed 613 records, 346 met definition case, median 21 years (range 5 to 71 ), most affected group 20 to 60 years $(51.6 \%$ ), incomplete primary education (33.5\%), single (61\%), rural area (71.3\%) and housework (64\%). Observed two violence types: physical (63\%) and sexual (37\%). Predominated Contusions $(57 \%)$ and rape $(37 \%)$. The spouse was the primary aggressor (20\%). Municipalities with higher prevalence rates were Marcala and San Jose with 11.6 and 8.7 per thousand, respectively. Only effect observed: pregnancy (12), 18\% victims of rape.

Conclusions Domestic violence present higher proportion on less educated, single women. As a limiting, are recorded only women who be attended by IML. We recommend implementing injury surveillance at other institutions, and disseminate results to other organisation to implement control measures and prevention.

\section{DOMESTIC VIOLENCE AMONG WOMEN ATTENDING THE FORENSIC MEDICINE INSTITUTE MARCALA, DEPARTMENT OF LA PAZ, HONDURAS, JUNE 2007 TO NOVEMBER 2009}

E E Lopez* Correspondence: Secretara de Salud de Honduras, C.A., Avenida Cervantes, contiguo a correo nacional, Direccin General de Vigilancia, Tegucigalpa Honduras

\subsection{6/ip.2010.029215.865}

Background In Honduras in 2008 were made 6.572 domestic violence complaints. At the Marcala Forensic Medicine Institute (IML), the leading injury cause complaint by women is domestic violence; the IML covers 10 municipalities, 57 833 women (51\%). No previous studies, being necessary to determine the domestic violence prevalence, epidemiological 